\title{
Advanced glycation end products and adipocytokines and oxidative stress in placental tissues of pregnant women with gestational diabetes mellitus
}

\author{
HONGXIA LI ${ }^{1}$, AIHONG DONG ${ }^{2}$ and XIAOXIA LV ${ }^{3}$ \\ ${ }^{1}$ Department of Geriatrics, Binzhou City Center Hospital, Binzhou, Shandong 251700; ${ }^{2}$ The Second Branch \\ of General Medicine, Binzhou People's Hospital, Binzhou, Shandong 256610; ${ }^{3}$ Department of Obstetrics, \\ Tengzhou Central People's Hospital, Tengzhou, Shandong 277500, P.R. China
}

Received March 22, 2019; Accepted May 20, 2019

DOI: $10.3892 / \mathrm{etm} .2019 .7623$

\begin{abstract}
Correlation between expression levels of advanced glycation end products (AGEs) and adipocytokines and oxidative stress index malondialdehyde (MDA) in placental tissues of pregnant women with gestational diabetes mellitus (GDM) was investigated. Seventy-two cases of GDM pregnant women who received routine prenatal examination and gave birth in the Department of Obstetrics, Binzhou City Center Hospital from March 2016 to May 2017 were collected as the observation group. Another 80 cases of normal pregnant women who gave birth at the same time were selected as the control group. Enzyme linked immunosorbent assay (ELISA) was used to detect the expression levels of AGEs, visfatin, APN and IL-6 in the lysate of placental tissues. MDA levels were measured by thiobarbituric acid method. Correlation of expression levels of AGEs, visfatin, APN, IL-6 and MDA were analyzed. The expression level of MDA in placental tissues of the observation group was significantly higher than that of the control group $(\mathrm{t}=16.44, \mathrm{P}<0.001)$. The correlation of expression levels between AGEs, adipocytokines and MDA in placental tissues of the two groups was analyzed, and it was found that the expression levels of AGEs, visfatin and IL- 6 in the two groups were positively correlated with MDA. There was a significantly negative correlation between APN and MDA in the two groups. The incidence of cesarean section, neonatal hypoglycemia, fetal distress and macrosomia in the observation group was significantly higher than that in the control group $(\mathrm{P}<0.05)$. There was no significant difference in the incidence of membrane rupture and premature birth between the two groups $(\mathrm{P}>0.05)$. In
\end{abstract}

Correspondence to: Dr Xiaoxia Lv, Department of Obstetrics, Tengzhou Central People's Hospital, 181 Xingtan Road, Tengzhou, Shandong 277500, P.R. China

E-mail: rxdr53@163.com

Key words: gestational diabetes mellitus, glycation end products, adipocytokines, oxidative stress conclusion, the expression levels of AGEs, visfatin and IL-6 in placental tissues of GDM pregnant women are positively correlated with MDA. There is a significant negative correlation between APN and MDA, and they play an important role in the pathogenesis of GDM.

\section{Introduction}

Gestational diabetes mellitus (GDM) is a common metabolic complication (1), which refers to the occurrence of symptoms such as abnormal glucose tolerance or glucose intolerance in different degrees during pregnancy, posing a great threat to the health of pregnant women and the fetus (2). In recent years, the incidence of GDM has gradually increased (3). GDM is a high-risk pregnancy, which will cause adverse effects on mother and baby. Before the treatment, the preperinatal mortality is approximately $40 \%$, and the maternal mortality is up to $27-30 \%(4,5)$. Placenta is an essential organ for babies' growth and development. During normal and pathological pregnancy, placenta can adapt to changes in intrauterine environment (6).

The AGEs-RAGE signaling pathway, formed by advanced glycation end product receptor (RAGE) and its ligands, advanced glycation end products (AGEs), is closely related to the occurrence and development of glucose metabolism disorders, and can activate inflammatory reactions and oxidative stress (7). The AGEs accumulation caused by persistent hyperglycemia during gestation is one of the main factors leading to abnormal fetal development (8). Visfatin, a newly discovered adipocytokine, is mainly secreted by visceral fat cells and is related to insulin secretion, glucose uptake and abnormal glucose tolerance (9). Interleukin-6 (IL-6), an important chronic inflammatory cytokine secreted by adipose tissue, is an adipocytokine and is associated with states of various insulin resistance (IR) in the body and can be released from the placenta (10). Adiponectin (APN) is a biologically active peptide hormone secreted by fat cells, which can be used to enhance insulin sensitivity, it is anti-inflammatory, and maintains the body's glucose metabolism balance (11). Studies have shown that inflammatory factors and adipokines are significantly associated with IR formation (12). 
Oxidative stress plays an important role in GDM (13). It is caused by an imbalance between the oxidant and the antioxidant (14). Oxidative stress is considered to be a causative factor in human pregnancy-related diseases, such as fetal death, pre-eclampsia, and intrauterine growth restriction (15). Malondialdehyde (MDA) is a product of lipid peroxidation and is produced by the degradation of phospholipids induced by reactive oxygen species (ROS) under pathogenic conditions (16). Changes in MDA levels can be used to reflect the degree of oxidative damage in the body (17). At present, there are few studies on the correlation between adipokines and oxidative stress in GDM.

In this study, the correction between AGEs, visfatin, APN, IL-6 and MDA was investigated by detecting the expression levels of AGEs and adipocytokines (visfatin, APN, IL-6) in placental tissues of pregnant women with GDM, to further improve the diagnosis and treatment of GDM and provide a reference for the pathogenesis of GDM.

\section{Patients and methods}

Methods. Seventy-two cases of GDM pregnant women who underwent routine prenatal examination and delivery in the Department of Obstetrics, Binzhou City Center Hospital (Binzhou, China) from March 2016 to May 2017 were enrolled as the observation group. Glucose tolerance test (OGTT) (75 g) was performed at 24-28 weeks of gestation. The diagnosis was made according to the International Association of Diabetes and Pregnancy Study Groups (IADPSG) standard (18). The mean age was $28.76 \pm 4.58$ years, the pre-pregnancy body mass index was $23.17 \pm 3.16 \mathrm{~kg} / \mathrm{m}^{2}$, and the mean gestational age was $38.82 \pm 1.18$ weeks; another 80 cases of normal pregnant women who were delivered at the same time were selected as the control group, with an average age of $27.99 \pm 5.82$ years, a pre-pregnancy body mass index of $22.86 \pm 2.66 \mathrm{~kg} / \mathrm{m}^{2}$, and an average gestational age of $39.11 \pm 1.03$ weeks.

Inclusion criteria were: Patients with singleton pregnancy, with no previous heart, liver and kidney disease, chronic hypertension and diabetes, and no dietary restrictions, with complete clinical data, without any smoking, drinking or other harmful habits.

Exclusion criteria were: Patients taking drugs affecting blood glucose metabolism three months before pregnancy, with premature rupture of the membranes, with a recent history of infection, with family hereditary mental illness, and with inactive cooperation with inspections.

The study was approved by the Ethics Committee of Binzhou City Center Hospital. Patients who participated in this research had complete clinical data. The signed informed consents were obtained from the patients or the guardians.

Specimen collection. Within $4 \mathrm{~h}$ after delivery of the placenta, 3 samples of placental tissue in sterile state were obtained from the center of the placenta maternal surface, each approximately $1 \times 1 \times 1 \mathrm{~cm}$ in size; avoiding the bleeding, infarct and calcification area. Tissue was washed repeatedly with sterilized physiological saline, and gauze used to remove water. Specimens under aseptic condition were cut up, RIPA lysate (Shanghai Yisheng Biological Technology Co., Ltd.) was used for pyrolysis, and then were ground into homogenate, centrifuged at $10,000 \mathrm{x}$ g for $15 \mathrm{~min}$ at $4^{\circ} \mathrm{C}$, finally the supernatant was taken into the trace centrifuge tube, stored at $-80^{\circ} \mathrm{C}$ for later use.

Detection method. The expression levels of AGEs, visfatin, APN and IL-6 in the placental tissue lysate were detected by enzyme-linked immunosorbent assay (ELISA), and the standard well, the sample well and the blank well (no samples and enzyme-labeled reagents were added, and the other steps were the same) were set, respectively. First, $50 \mu 1$ of standard sample was added accurately on the enzyme-labeled coated plate, $40 \mu \mathrm{l}$ of diluent was added in the sample well, then $10 \mu \mathrm{l}$ of sample to be tested was added. Plate membrane was used to seal the plate, and incubated at $37^{\circ} \mathrm{C}$ for $30 \mathrm{~min}$. Then the plate membrane was peeled off, the liquid was discarded, dried, and each well was filled with scrubbing liquid, discarded after standing, this was repeated five times, and then patted dry. In addition to blank wells, $50 \mu \mathrm{l}$ of enzyme-labeled reagent was added to each well for incubation and washing. After that, $50 \mu \mathrm{l}$ of chromogenic agent A and $50 \mu \mathrm{l}$ of chromogenic agent $\mathrm{B}$ were added to each well, shaked gently, and developed at $37^{\circ} \mathrm{C}$ for $15 \mathrm{~min}$ in the dark. Then $50 \mu \mathrm{l}$ of stopping solution was added to each well to immediately terminate the reaction when the blue turned yellow. The measurement was carried out within $15 \mathrm{~min}$ after the addition of the stopping solution, the blank well was used to adjust to zero and the absorbance (OD value) of each well was measured at the wavelength of $450 \mathrm{~nm}$. ELISA kits of AGEs were provided by Wuhan Mossak Biotechnology Co., Ltd., while ELISA kits of visfatin, APN and IL-6 were from Shanghai Jining Industry Co., Ltd. SK201 microplate reader was from Shenzhen Shengxinkang Technology Co., Ltd.

Level of MDA was measured by thiobarbituric acid method. Samples were taken and added with trichloroacetic acid and a small amount of quartz sand to grind, and then trichloroacetic acid was added to fully grind them. After centrifugation at $3,680 \mathrm{x}$ g for $10 \mathrm{~min}$ at $20^{\circ} \mathrm{C}, 2 \mathrm{ml}$ of supernates (sample suspension buffer) were taken and added with $2 \mathrm{ml}$ of $0.6 \%$ thiobarbituric acid, mixed and heated in a boiling water bath for $10 \mathrm{~min}$, cooled, and $2 \mathrm{ml}$ of distilled water was used to replace the extract as a control, and the OD value was measured at 532, 450 and $600 \mathrm{~nm}$. The kit provided was by Nanjing Jiancheng Biological Engineering Co., Ltd and it was performed in strict accordance with the instructions.

Observational indicators. Expression levels of AGEs, adipocytokines and MDA in placental tissues of the two groups were detected, and differences between two groups were compared. Correlation between MDA and expression levels of AGEs, visfatin, APN and IL-6 was analyzed.

Statistical processing. SPSS 19.0 software system (IBM Corp., Armonk, NY, USA) was used for statistical analysis of experimental data. Enumeration data were expressed as [n (\%)], and Chi-square test was used for comparison between groups. Measurement data were expressed as (mean $\pm \mathrm{SD}$ ), and independent sample t-test was used for comparison between groups. Pearson's correlation coefficients were used to analyze the correlation of bivariate normal distribution data. $\mathrm{P}<0.05$ was considered to indicate a statistically significant difference. 
Table I. Comparison of general clinical data between the two groups (mean $\pm \mathrm{SD}) /[\mathrm{n}(\%)]$.

\begin{tabular}{|c|c|c|c|c|}
\hline Factors & $\begin{array}{l}\text { Observation } \\
\text { group }(n=72)\end{array}$ & $\begin{array}{l}\text { Control group } \\
\quad(\mathrm{n}=80)\end{array}$ & $\chi^{2} / \mathrm{t}$ value & P-value \\
\hline Age (years) & $28.76 \pm 4.58$ & $27.99 \pm 5.82$ & 0.900 & 0.370 \\
\hline Body mass index before pregnancy $\left(\mathrm{kg} / \mathrm{m}^{2}\right)$ & $23.17 \pm 3.16$ & $22.86 \pm 2.66$ & 0.656 & 0.513 \\
\hline \multicolumn{5}{|l|}{ History of childbirth } \\
\hline Yes & $16(22.2)$ & $20(25.0)$ & & \\
\hline No & $56(77.8)$ & $60(75.0)$ & & \\
\hline \multicolumn{5}{|l|}{ History of hypertension } \\
\hline Yes & $8(11.1)$ & $12(15.0)$ & & \\
\hline No & $64(88.9)$ & $68(85.0)$ & & \\
\hline \multicolumn{5}{|l|}{ Ethnicity } \\
\hline Han & $67(93.1)$ & $71(88.8)$ & & \\
\hline Rest & $5(6.9)$ & $9(11.2)$ & & \\
\hline Gestational age (weeks) & $38.82 \pm 1.18$ & $39.11 \pm 1.03$ & 1.618 & 0.108 \\
\hline Systolic blood pressure (mmHg) & $117.37 \pm 12.87$ & $118.28 \pm 12.76$ & 0.437 & 0.663 \\
\hline Diastolic blood pressure (mmHg) & $75.89 \pm 7.96$ & $76.08 \pm 7.57$ & 0.151 & 0.880 \\
\hline Fasting blood-glucose (mmol/l) & $6.76 \pm 0.85$ & $5.22 \pm 0.67$ & 12.47 & $<0.001$ \\
\hline
\end{tabular}

SD, standard deviation.

Table II. Comparison of expression levels of AGEs, visfatin, APN and IL-6 in placental tissues between the two groups $($ mean $\pm \mathrm{SD})$.

\begin{tabular}{|c|c|c|c|c|c|}
\hline Group & No. of cases & AGEs (ng/ml) & Visfatin $(\mathrm{ng} / \mathrm{ml})$ & $\mathrm{APN}(\mathrm{mg} / \mathrm{l})$ & IL-6 (ng/ml) \\
\hline Observation group $(n=72)$ & 72 & $54.27 \pm 18.28$ & $0.46 \pm 0.23$ & $0.70 \pm 0.09$ & $1.44 \pm 0.58$ \\
\hline Control group $(\mathrm{n}=80)$ & 80 & $32.18 \pm 12.12$ & $0.52 \pm 0.25$ & $1.29 \pm 0.14$ & $0.78 \pm 0.39$ \\
\hline t value & & 8.861 & 1.534 & 30.53 & 8.305 \\
\hline P-value & & $<0.001$ & 0.127 & $<0.001$ & $<0.001$ \\
\hline
\end{tabular}

AGEs, advanced glycation end products; APN, Adiponectin; IL-6, Interleukin-6.

\section{Results}

Comparison of general clinical data. General clinical data of the two groups were collected. Observation and control group showed no significant difference in age, body mass index before pregnancy, history of childbirth, history of hypertension, ethnicity, gestational age, systolic blood pressure, diastolic blood pressure and other aspects $(\mathrm{P}>0.05)$, which were comparable. Fasting blood-glucose of observation group was significantly higher than that of control group $(\mathrm{P}<0.05)$ (Table I).

Expression levels of AGEs and adipocytokines in placental tissues of the two groups. Expression levels of AGEs and adipocytokines in placental tissues of observation and control group were detected. Results showed that the expression levels of AGEs and IL-6 in placental tissues of observation group were significantly higher than those of control group $(\mathrm{t}=8.861$, 8.305, $\mathrm{P}<0.001$ ). Expression level of APN in placental tissues of observation group was significantly lower than that of control
Table III. Expression levels of MDA in placental tissues of the two groups (mean $\pm \mathrm{SD}$ )

\begin{tabular}{lcc}
\hline Groups & No. of cases & MDA $(\mathrm{ng} / \mathrm{ml})$ \\
\hline Observation group $(\mathrm{n}=72)$ & 72 & $6.21 \pm 1.03$ \\
Control group $(\mathrm{n}=80)$ & 80 & $3.87 \pm 0.71$ \\
t value & & 16.44 \\
P-value & $<0.001$ \\
\hline
\end{tabular}

group, and difference was statistically significant $(\mathrm{t}=30.53$, $\mathrm{P}<0.001)$. There was no significant difference in expression of visfatin between the two groups $(\mathrm{P}>0.05)$ (Table II).

Expression levels of MDA in placental tissues of the two groups. The expression level of oxidative stress MDA in placental tissues of observation and control group was detected, and 


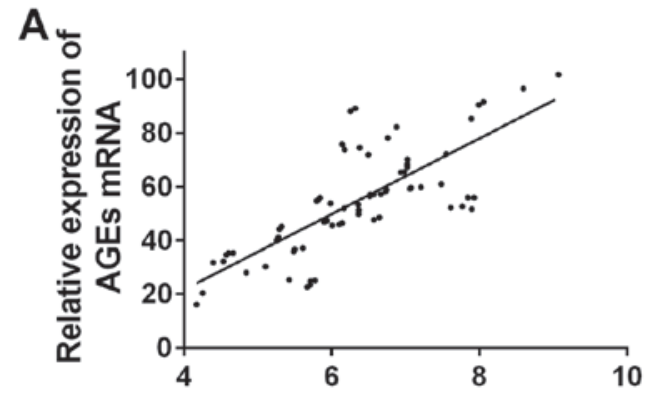

Relative expression of MDA mRNA

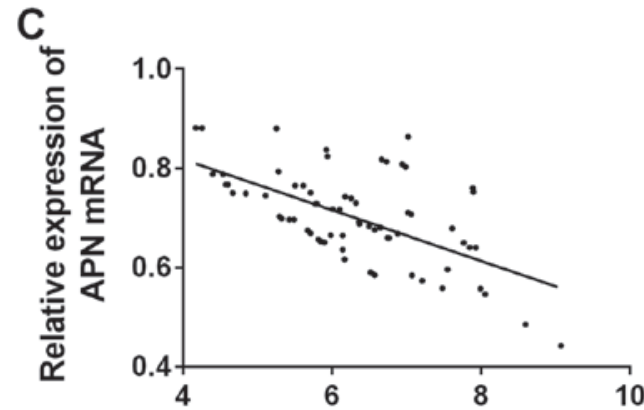

Relative expression of MDA mRNA

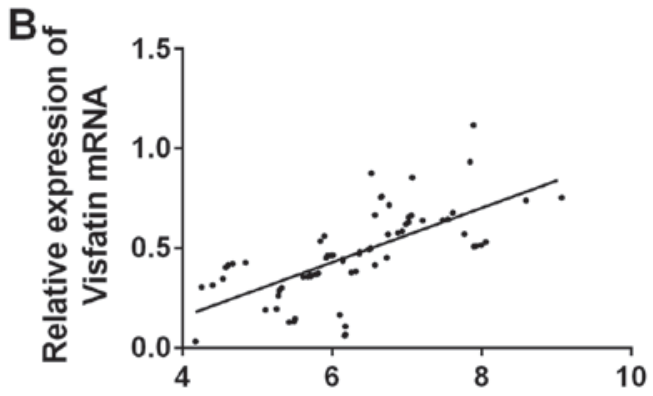

Relative expression of MDA mRNA

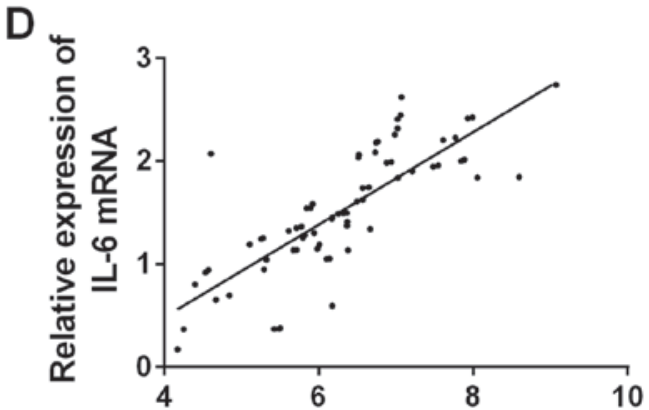

Relative expression of MDA mRNA

Figure 1. Pearson's correlation analysis of expression levels of AGEs, fat cytokines and MDA in the observation group showed that expression levels of (A) AGEs, (B) visfatin and (D) IL-6 were positively correlated with MDA ( $\mathrm{r}=0.757,0.454,0.792, \mathrm{P}<0.001)$. There was a significantly negative correlation between $(\mathrm{C})$ APN and MDA in the two groups ( $r=-0.602, \mathrm{P}<0.001)$.

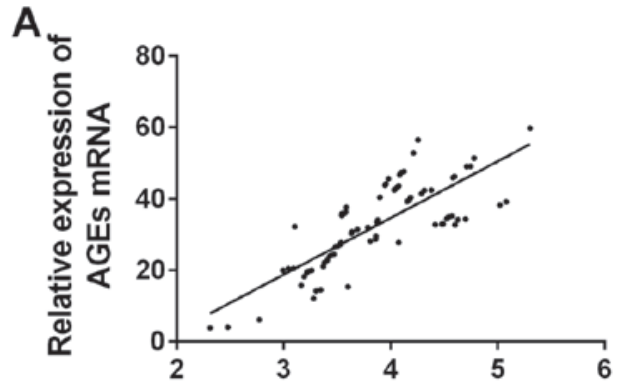

Relative expression of MDA mRNA

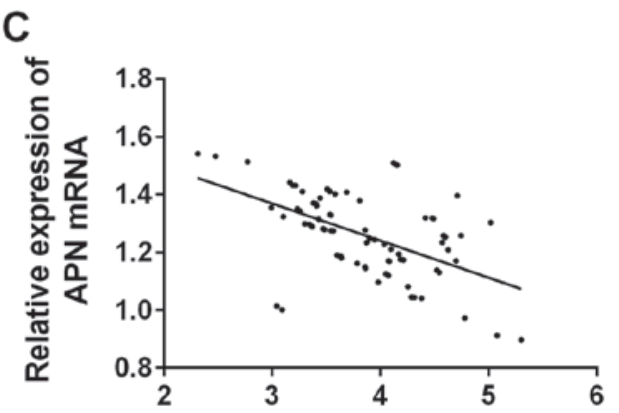

Relative expression of MDA mRNA

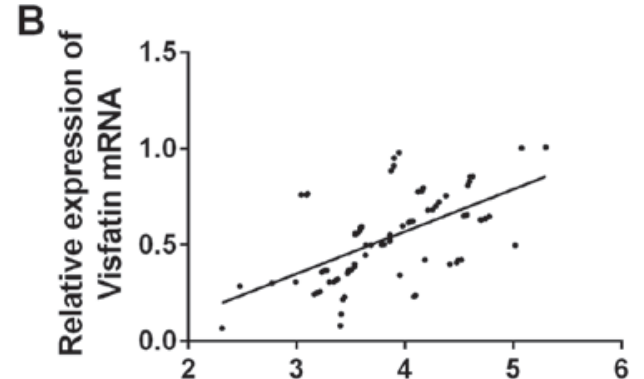

Relative expression of MDA mRNA

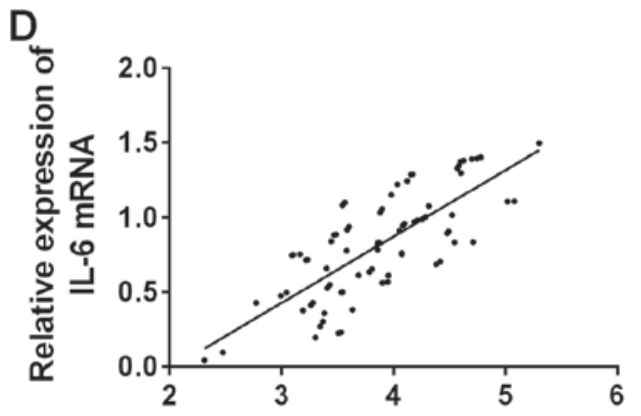

Relative expression of MDA mRNA

Figure 2. Pearson's correlation analysis of expression levels of AGEs, fat cytokines and MDA in the control group showed that the expression levels of (A) AGEs, (B) visfatin and (D) IL-6 were positively correlated with MDA ( $\mathrm{r}=0.794,0.573,0.763$, P $<0.001$ ). There was a significantly negative correlation between (C) APN and MDA in the two groups ( $\mathrm{r}=-0.544, \mathrm{P}<0.001)$.

results showed that the expression level of MDA in placental tissues of observation group was significantly higher than that of control group, and difference was statistically significant $(\mathrm{t}=16.44, \mathrm{P}<0.001)$ (Table III).
Correlation analysis between AGEs, adipocytokines and expression of MDA. As shown in Figs. 1 and 2, the correlation between AGEs, adipocytokines and expression of MDA in placental tissues of the two groups was analyzed. The 
Table IV. Correlation analysis between AGEs, visfatin, APN, IL-6 and expression of MDA.

\begin{tabular}{|c|c|c|c|c|c|c|c|c|}
\hline \multirow[b]{2}{*}{ Groups } & \multicolumn{2}{|c|}{ AGEs } & \multicolumn{2}{|c|}{ Visfatin } & \multicolumn{2}{|c|}{ APN } & \multicolumn{2}{|c|}{ IL-6 } \\
\hline & $\mathrm{r}$ & P-value & $\mathrm{r}$ & P-value & $\mathrm{r}$ & P-value & $\mathrm{r}$ & P-value \\
\hline Observation $(n=72)$ & 0.757 & $<0.001$ & 0.454 & $<0.001$ & -0.602 & $<0.001$ & 0.792 & $<0.001$ \\
\hline Control $(\mathrm{n}=80)$ & 0.794 & $<0.001$ & 0.573 & $<0.001$ & -0.544 & $<0.001$ & 0.763 & $<0.001$ \\
\hline
\end{tabular}

Table V. Comparison of pregnancy outcomes between the two groups [n (\%)].

\begin{tabular}{lcccccc}
\hline Group & $\begin{array}{c}\text { Cesarean } \\
\text { section }\end{array}$ & $\begin{array}{c}\text { Premature rupture } \\
\text { of membranes }\end{array}$ & $\begin{array}{c}\text { Premature } \\
\text { birth }\end{array}$ & $\begin{array}{c}\text { Neonatal } \\
\text { hypoglycemia }\end{array}$ & $\begin{array}{c}\text { Fetal } \\
\text { distress }\end{array}$ & Macrosomia \\
\hline Observation group $(\mathrm{n}=72)$ & $34(47.2)$ & $8(11.1)$ & $18(25.0)$ & $9(12.5)$ & $6(8.3)$ & $14(19.4)$ \\
Control group (n=80) & $13(16.3)$ & $6(7.5)$ & $15(18.6)$ & $2(2.5)$ & $1(1.3)$ & $5(6.3)$ \\
$\chi^{2}$ value & 17.020 & 0.591 & 0.871 & 5.645 & 4.328 & 6.032 \\
P-value & $<0.001$ & 0.442 & 0.351 & 0.018 & 0.038 & 0.014 \\
\hline
\end{tabular}

expression levels of AGEs, visfatin and IL-6 in the two groups were positively correlated with MDA. There was a significant negative correlation between APN and MDA in the two groups (Table IV).

Comparison of pregnancy outcomes between the two groups. There was no neonatal malformation or perinatal death in the two groups. The incidence of cesarean section, neonatal hypoglycemia, fetal distress and macrosomia in the observation group was significantly higher than that in the control group $(\mathrm{P}<0.05)$. There was no significant difference in the incidence of membrane rupture and preterm birth between the two groups $(\mathrm{P}>0.05)$ (Table $\mathrm{V})$.

\section{Discussion}

GDM not only leads to metabolic disorders in pregnant women, but may also lead to various early neonatal diseases (19). When the balance between the body's oxidative defense and free radical generation is broken, the target tissue will be damaged, thus forming oxidative stress (20). The function of tissue cells in GDM patients will be affected by the peroxidation state, and the function of islet $\beta$ cells is most severely affected, so it is extremely easy to cause cell damage or apoptosis (21).

AGEs is a stable covalent compound produced by non-enzymatic glycation of proteins, lipids or nucleic acids in long-term hyperglycemia (22). AGEs can promote intracellular signal transduction and mediate diabetic renal dysfunction (23). Visfatin promotes the formation of fat, which is highly expressed in visceral adipose tissues (24), and can also upregulate the production of pro-inflammatory cytokines by monocytes (25). APN is a plasma protein (26), which can promote the proliferation of mesangial cells in high-glucose environment, delay their apoptosis, reduce cell damage, and have a protective effect on cells (27). IL-6 is overexpressed in obesity and inflammation (28). It has been reported that the increased level of IL- 6 in the placenta of
GDM patients is caused by oxidative stress and inflammatory changes caused by hyperglycemia (24). MDA is one of the most reliable indicators of oxidative stress, and the increase of MDA level in diabetic patients is caused by the peroxidative decomposition of phospholipids caused by free oxygen radicals (29).

The expression levels of AGEs and adipocytokines in placental tissues of parturients in the observation group and the control group were detected. The results showed that the expression levels of AGEs and IL-6 in placental tissues of the observation group were significantly higher than those of the control group. The expression level of APN in placental tissues of the observation group was significantly lower than that of the control group. There was no significant difference in expression of visfatin in placental tissues between the two groups $(\mathrm{P}>0.05)$. It indicates that AGEs and IL-6 are highly expressed in placental tissues of GDM parturients, which is consistent with the studies of Voinov (30), and Wang et al (31). In this study, the expression of APN in placental tissues of GDM patients was low, indicating that there was abnormal regulation of adipokines in placenta. Studies have shown that compared with pregnant women with normal glucose tolerance, the expression of APN mRNA in GDM group was significantly decreased, and the expression change of APN in placental tissues was related to the expression of peroxisome proliferator activated receptor (PPAR- $\gamma$ ) and IL-6 (32). Relevant literature shows that the expression of visfatin in the female placental tissues of GDM was significantly higher than that in the normal control group, and the serum lipid concentration was positively correlated with the expression of visfatin in the placenta (33), and there are reports that the relative expression of visfatin mRNA in the placental tissues showed no statistically significant difference between the GDM group and the normal control group (34), and the results of this study are similar. It has been reported that GDM in pregnant women presents increased circulating oxidative stress hyperglycemia induction and decreased antioxidant 
enzymes $(35,36)$, suggesting that increased oxidative stress may have adverse effects on mother and fetus (37). In the present study, the expression level of MDA in placental tissues of the observation group and the control group was detected, and the results showed that the expression level of MDA in placental tissues of the observation group was significantly higher than that of the control group. In addition, studies have shown that MDA is highly expressed in the serum of pregnant women with GDM (16). This study showed that the expression levels of AGEs, visfatin and IL-6 in placental tissues of the two groups were positively correlated with MDA. There was a significantly negative correlation between APN and MDA in the two groups. The results suggested that AGEs, visfatin, IL-6 and APN might be related to oxidative stress in pregnant women with GDM. Bansal et al (38) indicated that AGEs and MDA in serum in type 2 diabetes mellitus patients with vascular complications were significantly positively correlated. Studies have reported that adipokines leptin and resistin are positively correlated with MDA in maternal blood of GDM pregnant women, and APN and oxidative stress are antagonistic to each other (39). However, whether there is interaction in placental tissues or not remains to be confirmed by further studies. There was no neonatal malformation or perinatal death in the two groups. The incidence of cesarean section, neonatal hypoglycemia, fetal distress and macrosomia in the observation group was significantly higher than that in the control group $(\mathrm{P}<0.05)$. There was no significant difference in the incidence of membrane abruption and premature birth between the two groups ( $\mathrm{P}>0.05)$. The results of Dutta et al (40) showed that oxidative stress was associated with cell cycle arrest and fetal membrane oxidative injury, which jointly determined adverse pregnancy outcomes and were important factors for premature rupture of membranes and spontaneous premature birth. Studies on the relationship between AGE level and perinatal outcome in pregnant women with GDM have shown that high expression of AGEs is a risk factor for abnormal perinatal outcome in GDM (30). However, whether the AGEs, adipocytokines and oxidative stress levels can be used as important indicators to predict the pregnancy outcome with GDM requires further studies by expanding the number of samples.

This investigation studied the correlation between AGEs, adipocytokines and oxidative stress in pregnant women with GDM, but the specific mechanism still needs to be further studied to provide a clearer reference for the pathogenesis, clinical diagnosis and treatment of GDM.

In conclusion, the expression levels of AGEs, visfatin and IL-6 in placental tissues of GDM pregnant women were positively correlated with MDA. APN and MDA showed a significant negative correlation, which together played an important role in the pathogenesis of GDM.

\section{Acknowledgements}

Not applicable.

\section{Funding}

No funding was received.

\section{Availability of data and materials}

The datasets used and/or analyzed during the present study are available from the corresponding author on reasonable request.

\section{Authors' contributions}

HL analyzed and interpreted the patients' data. AD was responsible for ELISA and thiobarbituric acid method. XL helped with statistical analysis. HL wrote the manuscript. All the authors read and approved the final manuscript.

\section{Ethics approval and consent to participate}

The study was approved by the Ethics Committee of Binzhou City Center Hospital (Binzhou, China). Patients who participated in this research had complete clinical data. The signed informed consents were obtained from the patients or the guardians.

\section{Patient consent for publication}

Not applicable.

\section{Competing interests}

The authors declare that they have no competing interests.

\section{References}

1. Buchanan TA, Xiang A, Kjos SL and Watanabe R: What is gestational diabetes? Diabetes Care 30 (Suppl 2): S105-S111, 2007.

2. Ghodke B, Pusukuru R and Mehta V: Association of lipid profile in pregnancy with preeclampsia, gestational diabetes mellitus, and preterm delivery. Cureus 9: e1420, 2017.

3 . Kang MJ: The adiposity rebound in the 21 st century children: Meaning for what? Korean J Pediatr 61: 375-380, 2018.

4. Vargas-Terrones M, Nagpal TS and Barakat R: Impact of exercise during pregnancy on gestational weight gain and birth weight: An overview. Braz J Phys Ther 23: 164-169, 2019.

5. Poprawski G, Pietryga M, Zawiejska A, Iciek R, WenderOzegowska $\mathrm{E}$ and Brazert J: The impact of metabolic control on uteroplacental circulation parameters in pregnancies complicated by gestational hypertension and/or preeclampsia in pregnant women with pregestational diabetes. Ginekol Pol 86: 811-820, 2015 (In Polish).

6. Schmidt AM: Highlighting diabetes mellitus: The epidemic continues. Arterioscler Thromb Vasc Biol 38: e1-e8, 2018.

7. Belfiore A, Malaguarnera R, Vella V, Lawrence MC, Sciacca L, Frasca F, Morrione A and Vigneri R: Insulin receptor isoforms in physiology and disease: An updated view. Endocr Rev 38: 379-431, 2017.

8. van Rhijn-Brouwer FCC, Gremmels H, Fledderus JO and Verhaar MC: Mesenchymal stromal cell characteristics and regenerative potential in cardiovascular disease: Implications for cellular therapy. Cell Transplant 27: 765-785, 2018.

9. Abell SK, De Courten B, Boyle JA and Teede HJ: Inflammatory and other biomarkers: Role in pathophysiology and prediction of gestational diabetes mellitus. Int J Mol Sci 16: 13442-13473, 2015.

10. Sudharshana Murthy KA, Bhandiwada A, Chandan SL, Gowda SL and Sindhusree G: Evaluation of oxidative stress and proinflammatory cytokines in gestational diabetes mellitus and their correlation with pregnancy outcome. Indian J Endocrinol Metab 22: 79-84, 2018.

11. Badon SE, Zhu Y, Sridhar SB, Xu F, Lee C, Ehrlich SF, Quesenberry CP and Hedderson MM: A pre-pregnancy biomarker risk score improves prediction of future gestational diabetes. J Endocr Soc 2: 1158-1169, 2018. 
12. Low Birth Weight and Nephron Number Working Group: The Impact of kidney development on the life course: A consensus document for action. Nephron 136: 3-49, 2017.

13. Lappas M, Permezel M and Rice GE: Release of proinflammatory cytokines and 8-isoprostane from placenta, adipose tissue, and skeletal muscle from normal pregnant women and women with gestational diabetes mellitus. J Clin Endocrinol Metab 89: 5627-5633, 2004.

14. Ekun OA, Ogidi NO,LawalRA, Ogunmuyiwa OA,Umewune MC, Adefolaju FO, Oshundun MF and Oremosu AI: Interrelationship between markers of oxidative stress, inflammation and hematological parameters among preeclamptic Nigerian women. Med Sci Monit Basic Res 24: 225-231, 2018.

15. Al-Gubory KH, Fowler PA and Garrel C: The roles of cellular reactive oxygen species, oxidative stress and antioxidants in pregnancy outcomes. Int J Biochem Cell Biol 42: 1634-1650, 2010.

16. Zhang C, Yang Y, Chen R, Wei Y, Feng Y, Zheng W, Liao H and Zhang Z: Aberrant expression of oxidative stress related proteins affects the pregnancy outcome of gestational diabetes mellitus patients. Am J Transl Res 11: 269-279, 2019.

17. Xin G, Du J, Wang YT and Liang TT: Effect of oxidative stress on heme oxygenase-1 expression in patients with gestational diabetes mellitus. Exp Ther Med 7: 478-482, 2014

18. Schäfer-Graf UM, Gembruch U, Kainer F, Groten T, Hummel S, Hösli I, Grieshop M, Kaltheuner M, Bührer C, KautzkyWiller A, et al: Gestational diabetes mellitus (GDM) - diagnosis, treatment and follow-up. Guideline of the DDG and DGGG (S3 level, AWMF registry number 057/008, February 2018) Geburtshilfe Frauenheilkd 78: 1219-1231, 2018 (In German)

19. England L, Kotelchuck M, Wilson HG, Diop H, Oppedisano P, Kim SY, Cui X and Shapiro-Mendoza CK: Estimating the recurrence rate of gestational diabetes mellitus (GDM) in Massachusetts 1998-2007: Methods and findings. Matern Child Health J 19: 2303-2313, 2015.

20. Orr SK, Dachner N, Frank L and Tarasuk V: Relation between household food insecurity and breast feeding in Canada. CMAJ 190: E312-E319, 2018.

21. Wells JCK, Figueiroa JN and Alves JG: Maternal pelvic dimensions and neonatal size: Implications for growth plasticity in early life as adaptation. Evol Med Public Health 2017: 191-200, 2018.

22. Chen C, Gong W, Li C, Xiong F, Wang S, Huang J, Wang Y, Chen Z, Chen Q, Liu P, et al: Sphingosine kinase 1 mediates AGEs-induced fibronectin upregulation in diabetic nephropathy. Oncotarget 8: 78660-78676, 2017.

23. Manigrasso MB, Juranek J, Ramasamy R and Schmidt AM: Unlocking the biology of RAGE in diabetic microvascular complications. Trends Endocrinol Metab 25: 15-22, 2014.

24. Briana DD and Malamitsi-Puchner A: Reviews: Adipocytokines in normal and complicated pregnancies. Reprod Sci 16: 921-937, 2009.

25. Moschen AR, Kaser A, Enrich B, Mosheimer B, Theurl M, Niederegger $\mathrm{H}$ and Tilg $\mathrm{H}$ : Visfatin, an adipocytokine with proinflammatory and immunomodulating properties. J Immunol 178 : $1748-1758,2007$

26. Galic S, Oakhill JS and Steinberg GR: Adipose tissue as an endocrine organ. Mol Cell Endocrinol 316: 129-139, 2010.
27. Kukla M, Mazur W, Bułdak RJ and Zwirska-Korczala K: Potential role of leptin, adiponectin and three novel adipokines visfatin, chemerin and vaspin - in chronic hepatitis. Mol Med 17: 1397-1410, 2011.

28. Vozarova B, Weyer C, Hanson K, Tataranni PA, Bogardus C and Pratley RE: Circulating interleukin-6 in relation to adiposity, insulin action, and insulin secretion. Obes Res 9: 414-417, 2001.

29. Decroli E, Manaf A, Syahbuddin S, Syafrita Y and Dillasamola D: The correlation between malondialdehyde and nerve growth factor serum level with diabetic peripheral neuropathy score. Open Access Maced J Med Sci 7: 103-106, 2019.

30. Voinov VA: Therapeutic apheresis in metabolic syndrome Immunol Endocr Metab Agents Med Chem 18: 38-54, 2018.

31. Wang C, Guelfi KJ and Yang HX: Exercise and its role in gestational diabetes mellitus. Chronic Dis Transl Med 2: 208-214, 2016.

32. Pantham P, Aye IL and Powell TL: Inflammation in maternal obesity and gestational diabetes mellitus. Placenta 36: 709-715, 2015.

33. Ma Y, Cheng Y, Wang J, Cheng H, Zhou S and Li X: The changes of visfatin in serum and its expression in fat and placental tissue in pregnant women with gestational diabetes. Diabetes Res Clin Pract 90: 60-65, 2010.

34. Luo JX, Liu XH, Zhang L and He GL: The expression of visfatin in placenta in women with gestational diabetes mellitus. Sichuan Da Xue Xue Bao Yi Xue Ban 42: 204-207, 2011 (In Chinese).

35. Karacay O, Sepici-Dincel A, Karcaaltincaba D, Sahin D, Yalvaç S, Akyol M, Kandemir O and Altan N: A quantitative evaluation of total antioxidant status and oxidative stress markers in preeclampsia and gestational diabetic patients in 24-36 weeks of gestation. Diabetes Res Clin Pract 89: 231-238, 2010.

36. Lappas M, Hiden U, Desoye G, Froehlich J,Hauguel-de Mouzon S and Jawerbaum A: The role of oxidative stress in the pathophysiology of gestational diabetes mellitus. Antioxid Redox Signal 15: 3061-3100, 2011

37. Sultan S, Alzahrani N and Al-Sakkaf K: The postpartum effect of maternal diabetes on the circulating levels of sirtuins and superoxide dismutase. FEBS Open Bio 8: 256-263, 2018.

38. Bansal S, Chawla D, Siddarth M, Banerjee BD, Madhu SV and Tripathi AK: A study on serum advanced glycation end products and its association with oxidative stress and paraoxonase activity in type 2 diabetic patients with vascular complications. Clin Biochem 46: 109-114, 2013.

39. Brink HS, van der Lely AJ and van der Linden J: The potential role of biomarkers in predicting gestational diabetes. Endocr Connect 5: R26-R34, 2016.

40. Dutta EH, Behnia F, Boldogh I, Saade GR, Taylor BD, Kacerovský M and Menon R: Oxidative stress damage-associated molecular signaling pathways differentiate spontaneous preterm birth and preterm premature rupture of the membranes. Mol Hum Reprod 22: 143-157, 2016.

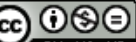

This work is licensed under a Creative Commons Attribution-NonCommercial-NoDerivatives 4.0 International (CC BY-NC-ND 4.0) License. 